\title{
Regional lung function in patients with increased unilateral transradiancy of the lung in the presence of cardiac disease
}

\author{
W. A. LITTLER ${ }^{1}$, C. C. EVANS, and J. B. MEADE \\ Regional Cardiothoracic Centre, Broadgreen Hospital, Liverpool
}

\begin{abstract}
Regional lung function has been studied with xenon-133 in two patients with unilateral transradiancy of the lung and coincidental cardiac disease. One patient had severe mitral stenosis with pulmonary venous and pulmonary arterial hypertension, the other had a secundum type of atrial septal defect with a pulmonary blood flow which was increased to 25 litres per minute. In both instances the overall perfusion of the transradiant lung was diminished but the regional distribution of blood flow was the same within both the 'normal' and the transradiant lung. In the patient with mitral stenosis there was an abnormal increase in upper zone perfusion resulting in a reversal of the normal pattern of pulmonary blood flow while in the patient with an atrial septal defect the blood flow difference between the upper and lower zones was decreased and thus the normal vertical gradient was less. These studies suggest that the hypoplastic pulmonary arteries in the transradiant lung reacted in the same way to alterations in pressure and flow as the vessels in the other lung.
\end{abstract}

A condition consisting of abnormal transradiancy of one lung has been known for several years by the eponym Macleod's syndrome (Macleod, 1954) and this subject has been extensively reviewed recently (Nairn and Prime, 1967; Warrell, Hughes, and Rosenzweig, 1970; British Medical Journal, 1971). While most authors are agreed that the affected lung usually shows evidence of obstructive emphysema and decreased perfusion there is still debate about the underlying mechanism. A recent British Medical Journal leader favours an obliterative bronchiolitis resulting from childhood infections as the cause and suggests that the term 'Macleod's syndrome' should be replaced by 'lobar bronchiolar obstruction with emphysema'. On the other hand, Belcher, Capel, Pattinson, and Smart (1959) have suggested that a congenital hypoplasia of the pulmonary artery is the predisposing factor, and Warrell and his colleagues (1970) believe that a pulmonary vascular abnormality is an important part of the condition.

The separate function of the two lungs has been studied by both differential bronchospirometry (Belcher et al., 1959; Fouché, Spears, and Ogilvie, 1960) and radioactive gas methods (Dollery and Hugh-Jones, 1963; Nairn and Prime, 1967; Warrell et al., 1970). All are agreed that blood 1Present address: The Radcliffe Infirmary, Oxford flow is greatly decreased in the affected lung while ventilation is diminished at normal tidal volumes.

In this paper we present the results of regional lung function studies performed in two patients who, in addition to unilateral transradiancy of the lung, had coincidental cardiac disease.

\section{METHODS}

The following tests of overall lung function were carried out using standard physiological techniques: (1) the subdivisions of lung volume including vital capacity (VC), functional residual capacity (FRC), and residual volume (RV); (2) the forced expiratory volume in one second (FEV $)$; and (3) transfer factor for carbon monoxide (TF) by the single breath technique.

Arterial blood samples were drawn anaerobically into heparinized syringes and analysed for $\mathrm{PO}_{2}$ (EIL Bishop electrode) and $\mathrm{PCO}_{2}$ (Severinghaus electrode).

The normal values for lung volumes were predicted from the formula of Baldwin, Cournand, and Richards (1948) and the normal values for the transfer factor were predicted from the formula of Ogilvie, Forster, Blackemore, and Morton (1957).

For regional lung function studies xenon-133 was used, employing the method of Dollery and Gillam (1963). The distribution of radioactivity was measured by scintillation counters that were moved vertically over the lungs during a breath-holding period. The 
patients were studied at rest in the seated position. Details of the techniques used have been fully described in previous publications from this laboratory (Brown, Kirk, and Seaton, 1969; Gaziano, Seaton, and Ogilvie, 1970; Littler, 1971).

Indiees for the distribution of blood flow and ventilation per unit alveolar volume were calculated at 2-cm intervals up each lung according to the formula of West (1966).

Combined right and left heart catheterization was performed for diagnostic purposes in both patients. The right heart was catheterized through the right saphenous vein. In case 1 left atrial catheterization was performed by transseptal puncture of the atrial septum and a second catheter was inserted percutaneously into the femoral artery and passed into the left ventricle. Pressures were recorded with the zero baseline $5 \mathrm{~cm}$ below the sternal angle. Cardiac output was calculated by the Fick method.

\section{PATIENTS}

CASE 1 This 37-year-old man had rheumatic fever during adolescence; after increasing breathlessness on exertion, he was found to have mitral stenosis in 1967. There was no definite history of childhood respiratory disease, but he had a productive cough during the winter months and smoked 20 cigarettes each day.

In 1967 the patient had undergone a closed mitral valvotomy. A chest radiograph taken at that time showed that the left lung was transradiant compared with the right.

He was referred to this centre 18 months later with progressive effort dyspnoea. Physical examination revealed a thin man who was in sinus rhythm and exhibited the physical signs of mixed mitral valve disease with predominant stenosis and, in addition, evidence of pulmonary arterial hypertension. On examination of the chest the breath sounds over the left lung were reduced compared with the right. An electrocardiogram revealed a $P$ mitrale and right axis deviation $\left(+125^{\circ}\right)$ while the chest radiograph showed 'mitralization' of the cardiac silhouette with a transradiant left lung (Fig. 1). Tests of overall lung function are presented in Table $I$ and show an obstructive pattern of ventilation with a normal transfer factor and normal blood gas tensions at rest.

Bilateral bronchography was performed and this showed a normal pattern on the right side whereas

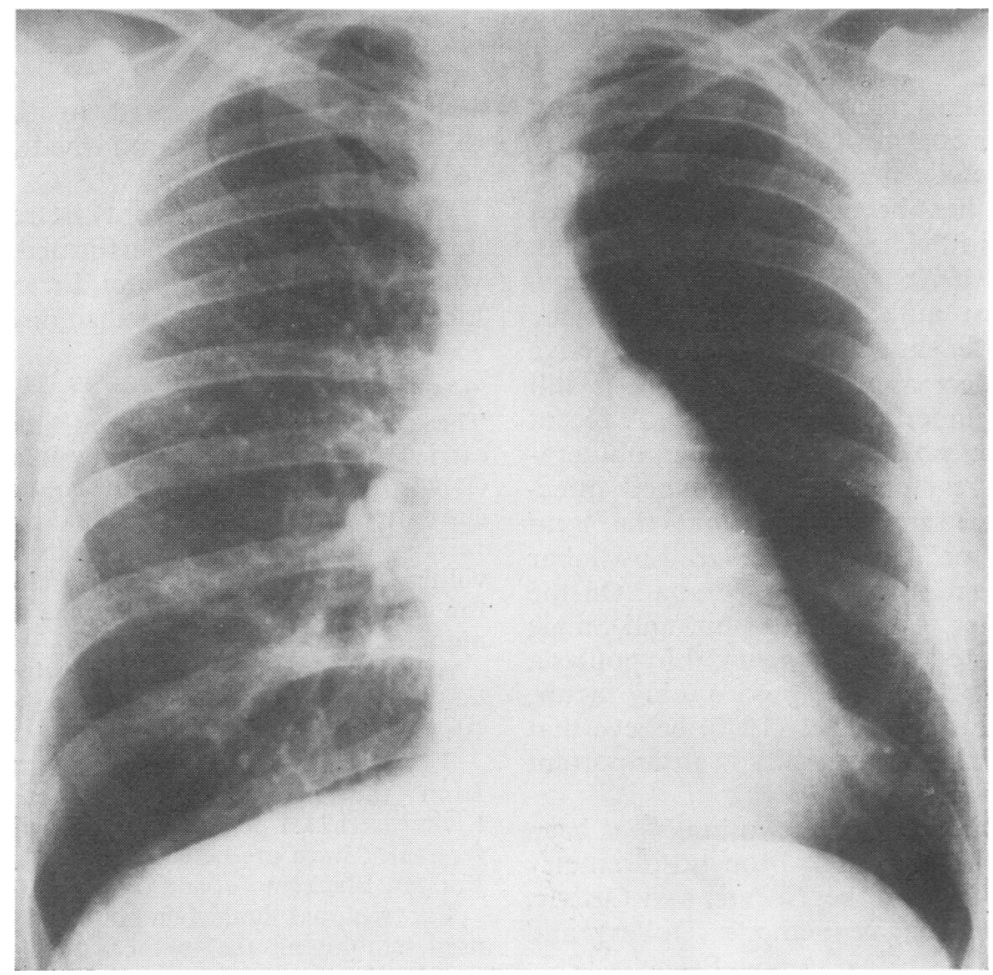

FIG. 1. Case 1. Chest radiograph showing increased transradiancy of the left lung with 'mitralization' of the heart. 
T A B L E I

TESTS OF OVERALL LUNG FUNCTION

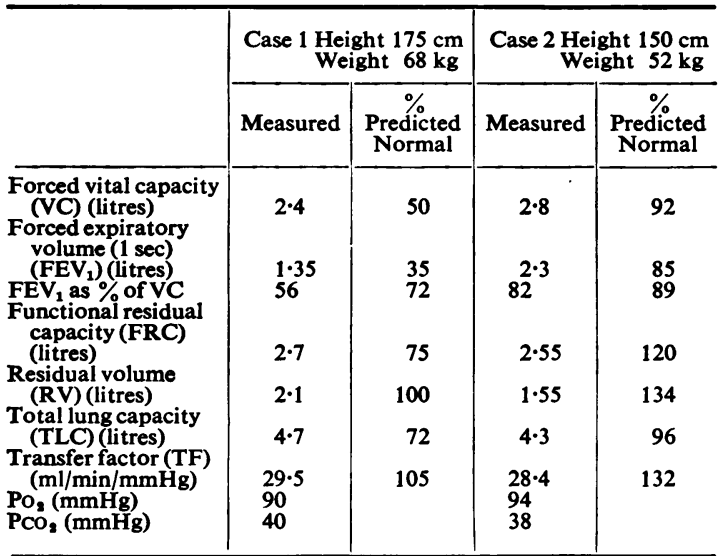

on the left side only the main bronchi filled adequately but there was no evidence of major bronchial obstruction.

The results of cardiac catheterization are listed in Table II and show that there was severe mitral stenosis with pulmonary arterial hypertension. A pulmonary angiogram (Fig. 2) showed that the left pulmonary artery was hypoplastic compared with the right.

Regional lung function studies were performed. The 'normal' (right) lung received $83 \%$ of the

T A B L E I I

CARDIAC CATHETER DATA

\begin{tabular}{l|c|c}
\hline & Case 1 & Case 2 \\
\hline Right atrium (mmHg) & 4 & 3 \\
& $1 \cdot 5(3)$ & $1(1 \cdot 5)$ \\
Right ventricle (mmHg) & 90 & 50 \\
& 3 & 0 \\
Pulmonary artery (mmHg) & 100 & 45 \\
& $50(63)$ & $18(25)$ \\
Left atrium (mmHg) & $\mathrm{a}=37$ & $\mathrm{a}=6$ \\
Left ventricle (mmHg) & $\mathrm{v}=38(33)$ & $\mathrm{v}=5(4)$ \\
LA-LV diastolic gradient (mmHg) & 120 & - \\
Pulmonary blood flow (litres/min) & 3 & - \\
Pulmonary vascular resistance & 36 & 0 \\
(dynes/cm/sec-5) & $5 \cdot 9$ & 25 \\
Pulmonary : systemic flow ratio & 409 & 35 \\
Cardiac index (litres/min/m ${ }^{2}$ ) & $1: 1$ & $2: 1$ \\
& $1 \cdot 83$ & $8 \cdot 50$
\end{tabular}

Mean pressures shown in parentheses.

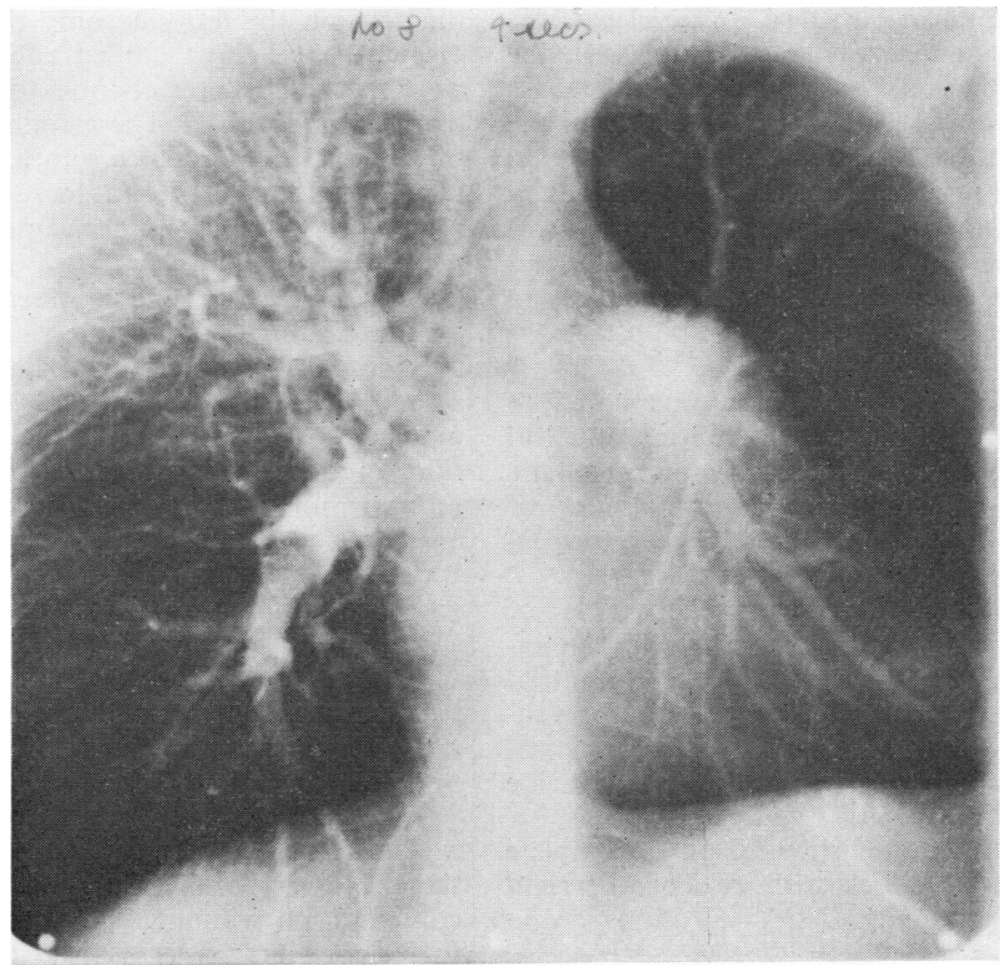

FIG. 2. Case 1. Anteroposterior pulmonary arterial angiogram. Note the difference in calibre between the vessels in the two lungs; those on the left are reduced in both size and number. 


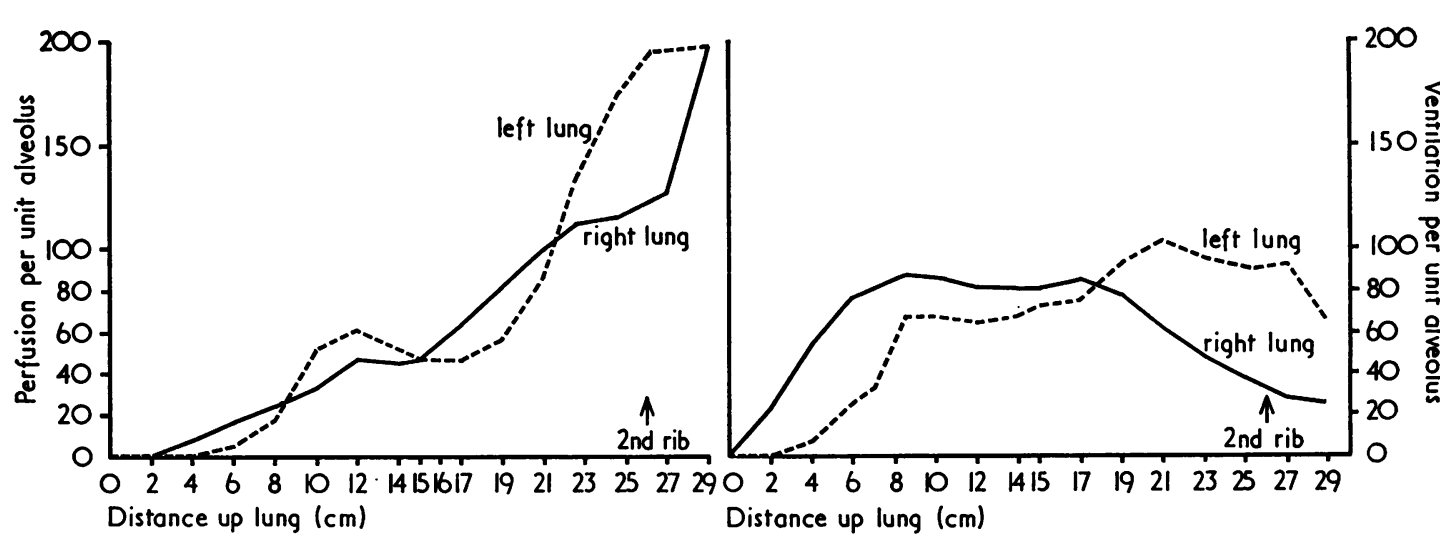

FIG. 3. Blood flow and ventilation per unit alveolus (at total lung capacity) plotted against lung distance in case 1 who $\frac{\vec{C}}{\vec{C}}$ had severe mitral stenosis. Note the inversion of the normal distribution of blood flow in both lungs and the diminished 3 'ventilation' in the lower zones.

pulmonary blood flow and $65 \%$ of ventilation. Figure 3 shows that the distribution of pulmonary blood flow within the two lungs is greatest at the apex and least at the base; that is a complete inversion of the normal pattern. Inspired gas was also distributed abnormally in both lungs. In the right lung, ventilation was decreased at the base but showed a normal 'fall off' at the apex. On the left side, ventilation was greater at the apex than at the base. The regional clearance of radioactivity after the injection of xenon-saline solution was abnormal in the left lung; traces of activity persisted 5 minutes after the injection, particularly in the upper zone.

CASE 2 This 21-year-old woman was noted to have a cardiac murmur at a routine medical examination. There was no history of rheumatic fever but she had had two severe attacks of pneumonia at the age of 14 and 16 years respectively. She smoked eight cigarettes daily.

Physical examination revealed a female of normal stature who was in sinus rhythm. She exhibited the physical signs of a secundum atrial septal defect with clinical evidence of right ventricular hypertrophy.

The breath sounds were reduced on the left side compared with the right.

An electrocardiogram showed an incomplete right bundle-branch block with evidence of right ventricular hypertrophy $\left(R_{1}=5 \mathrm{~mm}, \quad \mathrm{SV}_{5}=\right.$ $5 \mathrm{~mm}$ ).

A chest radiograph showed that the left lung was transradiant compared with the right (Fig. 4). Tests of overall lung function are listed in Table
I and show a relatively normal ventilatory capacity and lung volume with an increase in the transfer factor. Bilateral bronchography showed that theo right bronchial pattern was normal but unfor-s tunately on the left side only the left upper lobeo bronchus and lingula filled adequately and these $\frac{O}{\infty}$ were normal. The results of cardiac catheterization $\stackrel{\circ}{\circ}$ are listed in Table II. These confirmed the presence $\overrightarrow{\vec{\sigma}}$ of an atrial septal defect with a left-to-right shunt ${ }^{3}$ in the ratio of $2: 1$, an increase in pulmonary artery pressure but a normal pulmonary vascular. resistance. A pulmonary angiogram showed a reduction in the size and number of vessels in the left lung compared with the right (Fig. 5).

Regional lung function studies were performed.응 The 'normal' (right) lung received $65 \%$ of the pul-monary blood flow and $65 \%$ of alveolar ventila-o tion. Figure 6 shows that the distribution of pulmonary blood flow is similar within both lungs? and that although the lower zones are slightly $>$ better perfused than the upper zones the verticale gradient of blood flow is less steep than normal. N

Inspired gas was distributed relatively normally throughout both lungs apart from a reduction ac the extreme bases. The regional clearance of radioactivity after injection of xenon-saline soluo tion was normal.

Surgery has recently been undertaken to closethe septal defect and it was noted at the time that the left lung was small but had the normal bilobaro configuration without any obvious collapse, while the right lung was larger than normal ans extended in front of the pericardium toward the left side. The transradiant appearance of the leftr lung has persisted postoperatively (Fig. 7). 


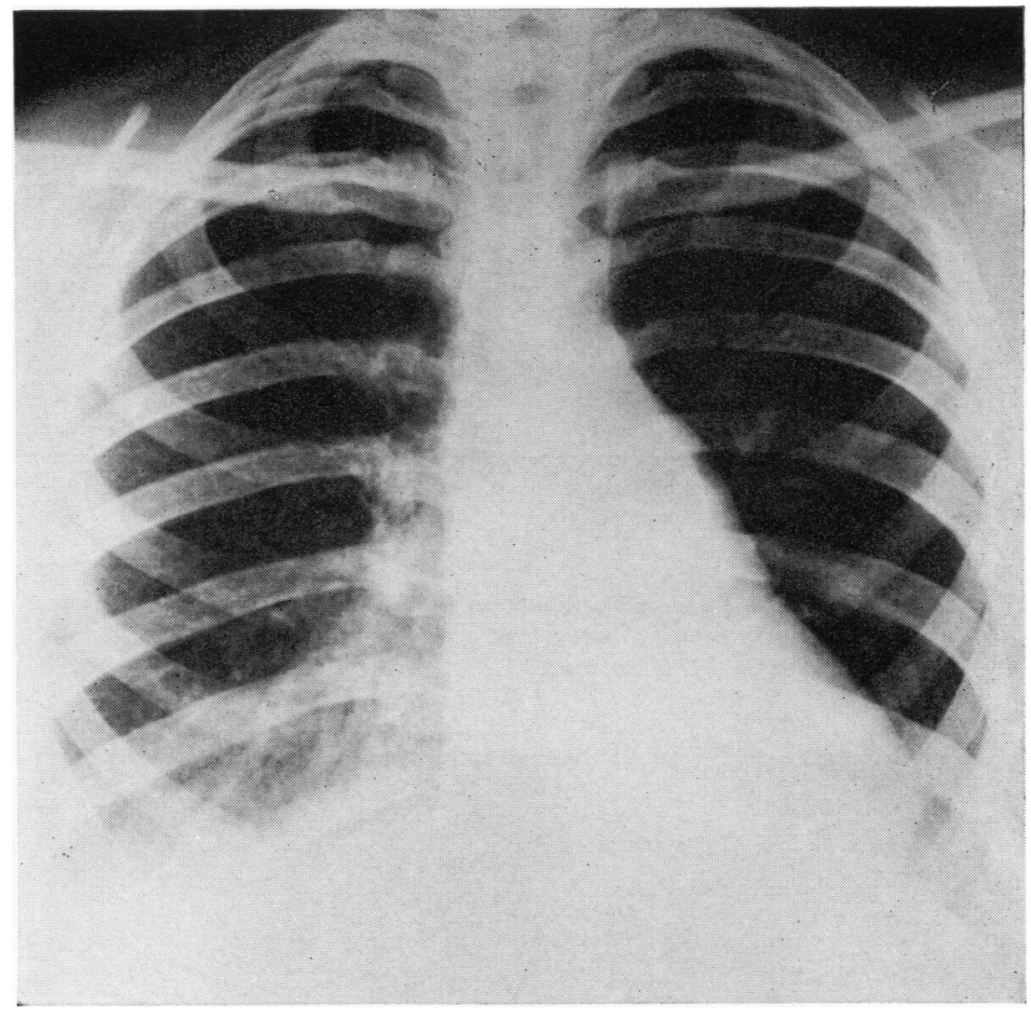

FIG. 4. Case 2. Chest radiograph showing increased transradiancy of the left lung; the heart shows a large pulmonary conus and small aortic knuckle.

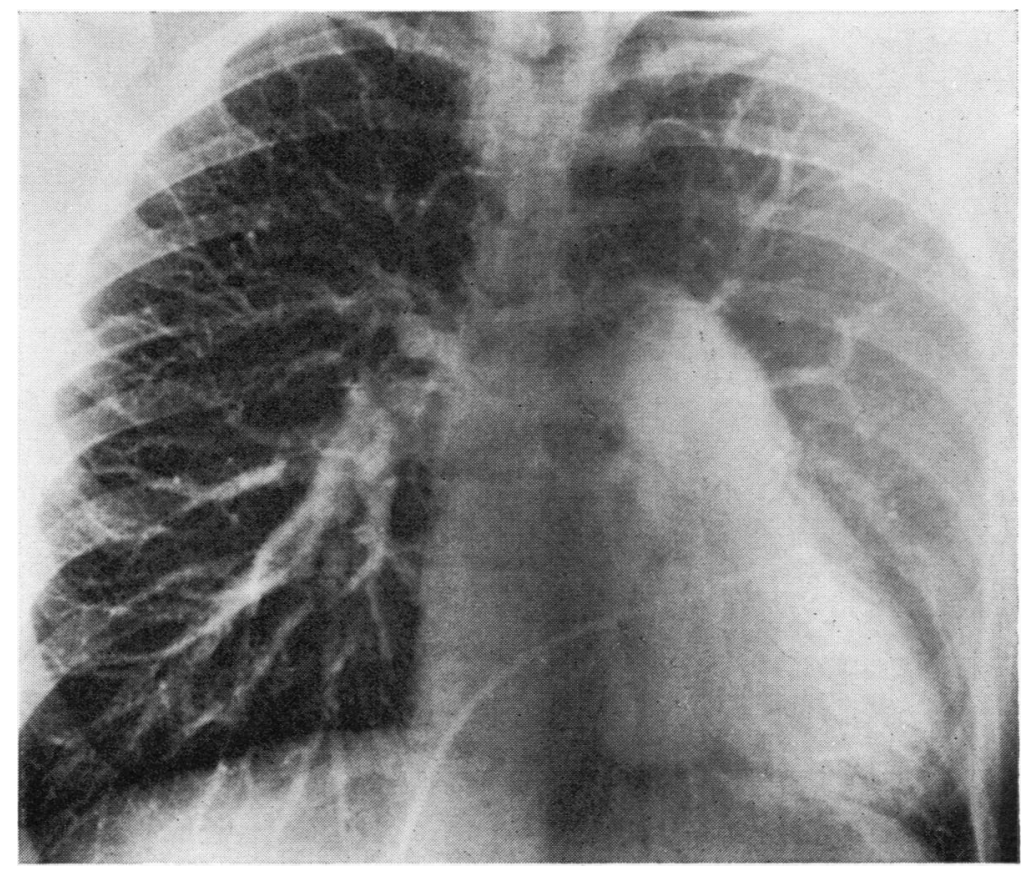

FIG. 5. Case 2. Pulmonary arterial angiogram. Note the reduced vascular pattern on the left side; the vessels are reduced in both size and number. 

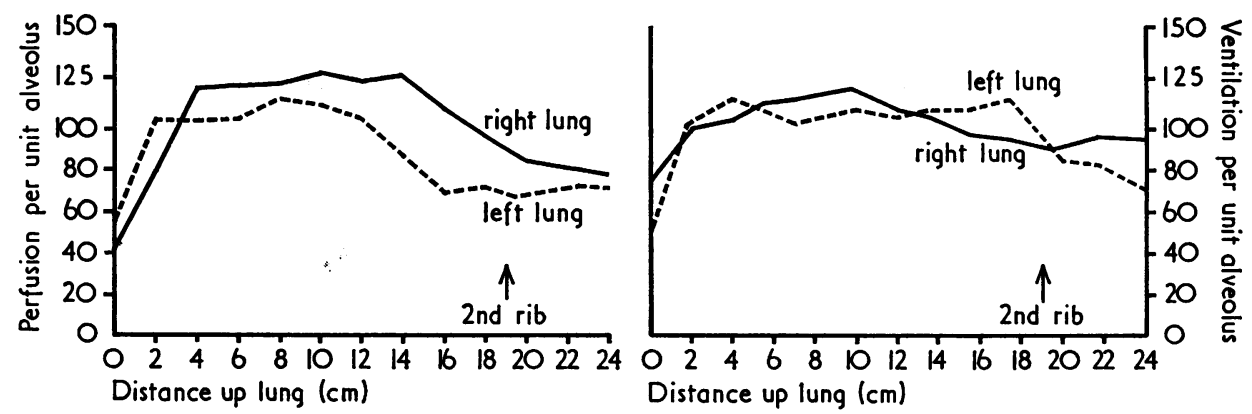

FIG. 6. Case 2. Blood flow and ventilation per unit alveolus (at total lung capacity) plotted against lung distance. The distribution of blood flow between apex and base is more even than normal in both lungs. 'Ventilation' appears normal on the right and is slightly diminished in the left lower zone.

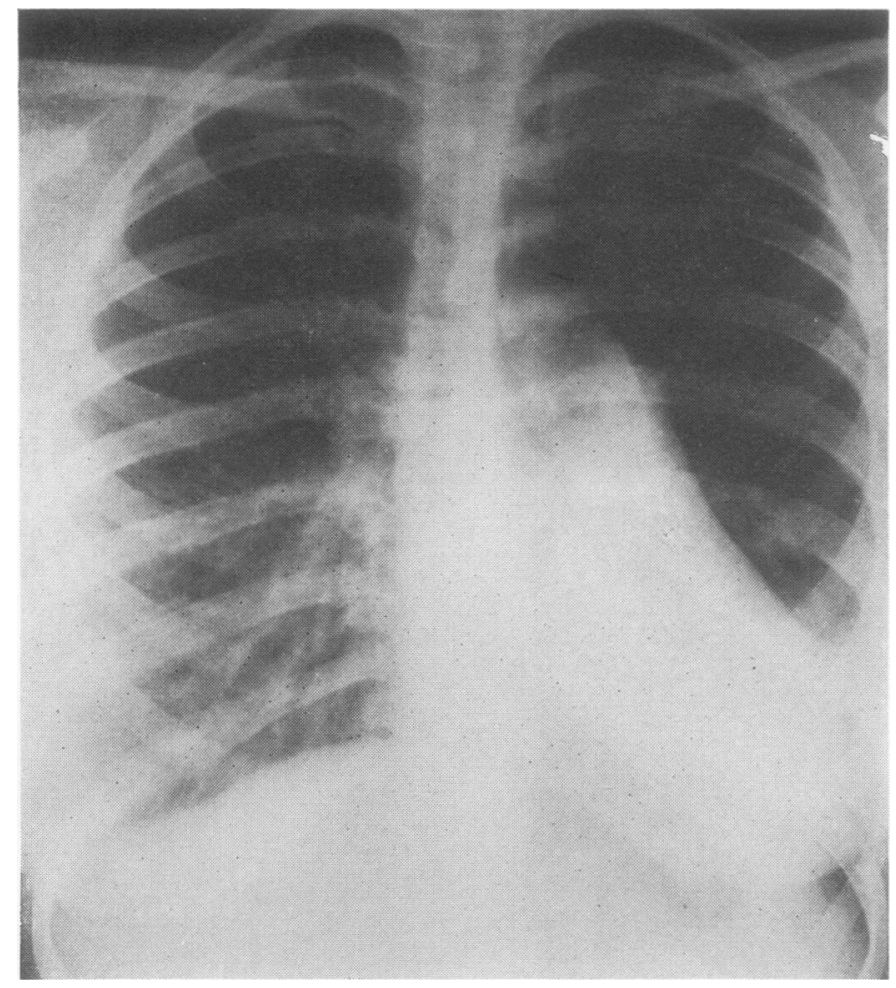

FIG. 7. Case 2. Postoperative chest radiograph. The breast shadow has obscured the lower zone on the left side but the increased transradiancy of that lung persists.

\section{DISCUSSION}

We believe that both our patients are examples of Macleod's syndrome. Each had abnormal transradiancy of one lung, decreased breath sounds over that lung, no major bronchial or pulmonary arterial occlusion, and physiological evidence of reduced pulmonary blood flow and ventilation on the affected side. We also believe that the coexistent cardiac lesions were coincidental, but the 
association of unilateral transradiancy and congenital cardiac disease has been reported by Yacoub, Belcher and Pattison (1965).

The main objective of this investigation was to compare the pattern of regional lung function in the two lungs in Macleod's syndrome. We were particularly interested to see if the effects of increased pulmonary vascular pressure and flow could be demonstrated in the transradiant lung. The main conclusion of this work is that the pulmonary vasculature reacts similarly in both the normal and transradiant lung.

Measurements of regional pulmonary blood flow in the upright position using radioactive xenon-133 show that flow is greatest at the base and decreases gradually to low values at the apex (Ball, Stewart, Newsham and Bates, 1962). West, Dollery and Naimark (1964) demonstrated that this pattern of flow is governed by the interrelationship of the effects of gravity, of lung inflation, and of changes in pulmonary arterial, venous, and alveolar pressure.

CASE 1 It has been shown that patients with raised pulmonary venous pressure caused by mitral stenosis (Dollery and West, 1960; Dawson, Kaneko, and McGregor, 1965 ; Seaton, 1971) or left ventricular failure (Ueda, Iio and Kaihara, 1964) have a reduction in the basal lung blood flow resulting in an inversion of the normal distribution. In patients with severe, long-standing disease this inversion is complete and is little affected by alteration in lung volume (Hughes, Glazier, Maloney, and West, 1968).

Friedman and Braunwald (1966) found a good correlation between the upper/lower zone ratio of blood flow and the level of pulmonary venous pressure while Seaton (1971) demonstrated that this increase in the upper to lower zone perfusion ratio was significantly related to the pulmonary arterial pressure and to a lesser extent to the left atrial pressure.

West (1969) believes that in the early stages of mitral stenosis increased interstitial pressure in the lower zones causes a diversion of blood from base to apex by isolating the 'extra-alveolar' vessels from the normal expanding pull of the lung parenchyma. This reversal is subsequently increased by vasoconstriction, muscular hypertrophy, and intimal proliferation of the arterioles in the lower zone. In severe pulmonary hypertension these vessels may be obliterated or thrombosed.

Our patient with mitral stenosis has a markedly raised left atrial pressure and pulmonary arterial hypertension with an increased vascular resistance.
In both lungs the pulmonary blood flow was much greater at the apex than at the base. In the transradiant lung, even though it only received some 15 to $20 \%$ of the overall pulmonary flow, the inverted pattern indicated that the pulmonary arterial system on that side was reacting like the vessels in the normal lung to the altered haemodynamics.

CASE 2 The normal flow difference between upper and lower zones decreases with increased pulmonary blood flow during exercise (Bryan et al., 1964). Patients with left-to-right intracardiac shunts with a high pulmonary blood flow also show a more even pattern of perfusion (Dollery et al., 1961).

Using $\mathrm{CO}_{2}$ labelled with oxygen-15 Dollery and his colleagues demonstrated a higher flow in the right upper zone in 10 patients with an atrial septal defect as opposed to the normal situation where blood flow to the left upper zone is slightly greater than to the right, presumably because of the inclination of the main pulmonary artery to the left. A few years earlier Fleming (1959) had studied 25 cases of atrial septal defect with differential bronchospirometry and had demonstrated a much increased oxygen uptake on the right compared with the left. Indeed in his illustrative examples the chest radiograph shows an oligaemic left lung and a plethoric right one, an appearance resembling the Macleod syndrome. However, Fleming also demonstrated that the ventilation and vital capacity were slightly less on the plethoric side which is opposite to the findings in Macleod's syndrome. Finally, postoperative chest radiographs in Fleming's cases, taken when the defect had been closed, showed equal vascularity of the two lungs. Fleming attempted to explain his findings by suggesting two possible mechanisms -ither the mechanical effect of an enlarged heart in the left chest impeding blood flow to that side, or preferential streaming of blood to the right lung across the defect.

We believe that our second case is an example of Macleod's syndrome. The pulmonary angiogram excluded a congenital stenosis of the left pulmonary artery but clearly showed poor vascularity on that side while the surgical findings excluded transradiancy secondary to a collapsed lower lobe. The pattern of blood flow within the transradiant lung resembled that on the other side and in both lungs there is a more even distribution of blood flow than in normal subjects; these changes are probably the result of the increased pulmonary arterial blood flow and pressure.

Several investigators have demonstrated hypo- 
plasia of the pulmonary arteries in the transradiant lung (Belcher et al., 1959); Reid and Simon, 1962). Belcher et al. (1959) used pulmonary angiography to show an overall reduction of $50 \%$ in the diameter of the pulmonary artery to the transradiant lung compared with the normal side. They argued that a reduction in pulmonary artery size secondary to lung disease was seldom below $60 \%$ of the normal diameter and concluded that there was a primary hypoplasia of the pulmonary artery.

In a careful pathological study of three transradiant lungs which had been surgically removed, Reid and Simon (1962) demonstrated that the pulmonary arteries were smaller in diameter than normal and in addition were hypoplastic in structure. However, these vessels were patent and branched normally and showed no evidence of thrombosis or arteritis. These authors were of the opinion that the changes were the result of infective damage to the airways of the lung in childhood. More recently, Warrell and his colleagues (1970) have suggested that the pulmonary vascular abnormality contributes to a limited exercise capacity in these patients by reducing the cardiac output.

We believe that we have demonstrated that the pulmonary artery on the transradiant side, despite being hypoplastic, reacts in the same way as the artery on the other side to alterations in pulmonary artery pressures and flow.

The patterns of regional ventilation demonstrated in these two patients are similar to the findings in other reported cases of Macleod's syndrome, the affected lung making a smaller contribution than the other to total alveolar ventilation. The regional abnormalities were greatest in the lower zones, confirming previous reports (Nairn and Prime, 1967 ; Warrell et al., 1970).

Seaton (1971) demonstrated that patients with mitral valve disease do not have significantly abnormal patterns of regional ventilation unless they have co-existent lung disease. Several authors have referred to the high incidence of generalized obstructive bronchitis in Macleod's syndrome (Nairn and Prime, 1967; Warrell et al., 1970). Our first case had clinical and physiological evidence of chronic bronchitis and we believe that this was responsible for the significant reduction of ventilation in the lower zone of the normal lung which has been noted previously in patients with chronic bronchitis (Gaziano et al., 1970) and in patients with Macleod's syndrome and chronic bronchitis (Warrell et al., 1970).

\section{REFERENCES}

Baldwin, E. de F., Cournand, A., and Richards, D. W. jun. $\frac{\overline{\bar{C}}}{\bar{D}}$ (1948). Pulmonary insufficiency: I. Physiological classification, clinical methods of analysis, standard values in
normal subjects. Medicine (Baltimore), 27, 243 .

Ball, W. C., Stewart, P. B., Newsham, L. G. S., and Bates, $\overrightarrow{0}$ D. V. (1962). Regional pulmonary function studied with. xenon $^{133}$. J. clin. Invest., 41, 519.

Belcher, J. R., Capel, L., Pattinson, J. N., and Smart, J.ळু (1959). Hypoplasia of the pulmonary arteries. Brit. J.P Dis. Chest, 53, 253.

British Medical Journal 1971), 3264.

Brown, I. K., Kirk, F., and Seaton, A. (1969). A scanner stander for pulmonary function studies. Brit. J. Radiol., 42, 545.

Bryan, A. C., Bentivoglio, L. G., Beerel, F., MacLeish, H.,응 Zidulka, A., and Bates, D. V. (1964). Factors affecting regional distribution of ventilation and perfusion in the lung. J. appl. Physiol., 19, 395.

Dawson, A., Kaneko, K., and McGregor, M. (1965). Regiona? lung function in patients with mitral stenosis studied with xenon ${ }^{133}$ during air and oxygen breathing. J. clin Invest., 44, 999.

Dollery, C. T., and Gillam, P. M. S. (1963). The distribution of blood and gas within the lungs measured by scanning

- and Hugh-Jones, P. (1963). The distribution of blood and gas within the lungs in disease. Brit. med. Bull., 19, 59.

— and West, J. B. (1960). Regional uptake of radioactive् oxygen, carbon monoxide and carbon dioxide in the lungs of patients with mitral stenosis. Circulat. Res., 8 765.

Wilcken, D. E. L., Goodwin, J. F., and Hugho Jones, P. (1961). Regional pulmonary blood flow in patients with circulatory shunts. Brit. Heart J., 23, 225

Fleming, H. A. (1959). Differential lung function in atriaP. septal defect. Circulation, 19, 856.

Fouché, R. F., Spears, J. R., and Ogilvie, C. (1960). Unilaterap emphysema. Brit. med.J., 1, 1312.

Friedman, W. F., and Braunwald, E. (1966). Alterations iniregional pulmonary blood flow in mitral valve disease studied by radioisotope scanning. Circulation, 34, 363.

Gaziano, D., Seaton, A., and Ogilvie, C. (1970). RegionaP lung function in patients with obstructive lung diseases? Brit. med. J., 2, 330.

Hughes, J. M. B., Glazier, J. B., Maloney, J. E., and West, J. B. (1968). Effect of lung volume on the distribution of pulmonary blood flow in man. Resp. Physiol., 4, 58.

Littler, W. A. (1971). M.D. thesis, University of Liverpool ${ }^{N}$

Macleod, W. M. (1954). Abnormal transradiancy of one lung. Thorax, 9, 147.

Nairn, J. R., and Prime, F. J. (1967). A physiological studx of Macleod's syndrome. Thorax, 22, 148.

Ogilvie, C. M., Forster, R. E., Blakemore, W. S., and Morton, J. W. (1957). A standardized breath holding technique for the clinical measurement of the diffusing capacity of the lung for carbon monoxide. J. clin. Invest.; 36, 1 .

Reid, L., and Simon, G. (1962). Unilateral lung trans radiancy. Thorax, 17, 230.

Seaton, A. (1971). M.D. thesis, University of Cambridge.

Ueda, H., Iio, M., and Kaihara, S. (1964). Determination of regional pulmonary blood flow in various cardio pulmonary disorders. Jap. Heart J., 5, 431. 
Warrell, D. A., Hughes, J. M. B., and Rosenzweig, D. Y. (1970). Cardiopulmonary performance at rest and during exercise in seven patients with increased transradiancy of one lung ('Macleod's syndrome'). Thorax, 25, 587.

West, J. B. (1966). The Use of Radioactive Materials in the Study of Lung Function. U.K.A.E.A. Radiochemical Centre, Amersham, England. (Medical Monographs No. 1).

(1969). Effects of interstitial pressure. In: The Pulmonary
Circulation and Interstitial Space, edited by A. P. Fishman and H. H. Hecht, p. 43. University of Chicago Press.

Dollery, C. T., and Naimark, A. (1964). Distribution of blood flow in isolated lung; relation to vascular and alveolar pressures. J. appl. Physiol., 19, 713.

Yacoub, M. H., Belcher, J. R., and Pattinson, J. N. (1965). Unilateral pulmonary artery hypoplasia associated with congenital cardiac anomalies. Brit. J. Dis. Chest., 59, 102. 